Tohoku J. Exp. Med., 2003, 199, 193-196

Case Report

\title{
Transient Relief of Asthma Symptoms during Jaundice: A Possible Beneficial Role of Bilirubin
}

\author{
Takashi Ohrui, Hiroyasu Yasuda, Mutsuo Yamaya, Toshifumi Matsui and \\ Hidetada Sasaki \\ Department of Geriatric and Respiratory Medicine, Tohoku University School \\ of Medicine, Sendai 980-8574
}

\begin{abstract}
Ohrui, T., Yasuda, H., Yamaya, M., Matsui, T. and Sasaki, H. Transient Relief of Asthma Symptoms during Jaundice: A Possible Beneficial Role of Bilirubin. Tohoku J. Exp. Med., 2003, 199 (3), 193-196_ Bilirubin arises from enzymatic reduction by biliverdin reductase of biliverdin, a product of heme oxygenase activity. Recent literature describes that bilirubin is a major physiologic antioxidant that can protect cells from chemical oxidants such as hydrogen peroxide. Recently, it has been reported that oxidative stress may play a crucial role in the pathogenesis of asthma. We report a case of complete resolution of persistent difficult-to-control asthma in accordance with increased levels of serum bilirubin due to acute hepatitis B. The present case suggests that anti-oxidative agents might be effective for the treatment of asthma. intractable asthma; oxidative stress; hyperbilirubinemia; antioxidant activity (C) 2003 Tohoku University Medical Press
\end{abstract}

Asthma is a disease of chronic airway inflammation characterized by reversible airway obstruction and increased airway responsiveness (Yamaya 2002). Recently, there is increasing evidence for a role of oxidative stress in the pathogenesis of asthma (Kelly et al. 1999; Dauletbaev et al. 2001). Bilirubin is a lipophilic linear tetrapyrrole, abundant in blood plasma, which occurs uniquely in mammals. It is the final product of heme catabolism, as heme oxygenase cleaves the heme ring to form the water-soluble biliverdin, which is reduced by biliverdin reductase to bilirubin (Baranamo et al. 2002). Bilirubin has long lacked any clear physiologic role. Recently, bilirubin and biliverdin have been shown to be highly potent scavengers of peroxyl radicals (Stocker et al. 1987; Wang et al. 2002) and it is proposed that bile pigments function as natural antioxidants (Baranamo et al. 2002). Here, we report, probably for the first time, a case of complete resolution of long-standing difficult-to-control asthma in accordance with increased levels of serum bilirubin due to acute hepatitis B.

\section{CASE REPORT}

An 18-year-old man was admitted to hospital due to malaise and jaundice. He had never

Received January 21, 2003; revision accepted for publication March 14, 2003.

Address for reprints: Hidetada Sasaki, M.D., Prof. and Chairman, Department of geriatric and respiratory

Medicine, Tohoku University School of Medicine, 1-1 Seiryomachi, Aoba-ku, Sendai 980-8574, Japan. e-mail: dept@geriat.med.tohoku.ac.jp 
been a smoker and had no previous medical history other than childhood asthma. Since age 15 years, he had been diagnosed with difficult-to-control asthma and had to use inhaled beclomethasone, $1200 \mu \mathrm{g}$ daily; inhaled fenoterol, $400 \mu \mathrm{g}$ daily; and oral theophylline, $400 \mathrm{mg}$ daily to control his asthma symptoms. Despite this treatment, he was symptomatic with an impaired exercise tolerance, nocturnal symptoms, and frequent use of rescue medication. Skin allergy tests were positive for house dust mite. On admission, he had clinical hepatomegaly. The serum aspartate transaminase level was $802 \mathrm{IU} /$ liter, serum alanine transaminase $914 \mathrm{IU} /$ liter, total bilirubin 3.2 $\mathrm{mg} / 100 \mathrm{ml}$ (conjugated bilirubin 79\%) and phosphatase alkaline $667 \mathrm{IU} /$ liter. The prothrombin time was 28 seconds. Virological markers indicated active $\mathrm{HB}$ virus infection with positive $\mathrm{HBsAg}$ and high titers of anti-HBc IgM antibody. The RNA or DNA assays by polymerase chain reaction for hepatitis $\mathrm{C}$ virus, cytomegalovirus, herpes simplex virus, and Epstein Barr virus were all negative. Acute hepatitis $\mathrm{B}$ was diagnosed on clinical and biological criteria and he received conservative treatment. The asthma medication was continued. After admission, the serum level of bilirubin gradually increased (maximum value $14.6 \mathrm{mg} / 100 \mathrm{ml}$ ). From 5 days until 24 days after admission, the mean morning peak expiratory flow rate and asthma symptom score (Nakasato et al. 1999) were significantly improved compared with those measured at day 1 , day 2 and day 3 after admission (432 [S.E. 27] liter/min. vs. 346 [18] liter/min., $p<0.05$ and 1.1 [0.2] vs. $8.2[2.6], p<0.05$, respectively), which is quite consistent with an elevation of serum bilirubin levels (Fig. 1). The mean exhaled carbon monoxide (CO) concentration, which is a marker for oxidative stress (Horvath et al. 1998), was significantly reduced during jaundice (measured at 11 days, 12 days and 13 days after admission) compared with baseline values (measured at 1 day, 2 days and 3 days after admission) $(1.2[0.2]$ vs. $6.2[0.9] \mathrm{ppm}, \quad p<0.01$, respectively). Serum theophylline concentrations were similar between day 2 and day 9 after admission (11.1 vs. $10.8 \mu \mathrm{g} / \mathrm{ml}$ ), when he took the same dose of a sustained-release of theophylline. He was relieved of asthma symptoms and asthma therapy was completely stopped at day 10 after admission, because drug induced liver damage had not been completely denied. How-

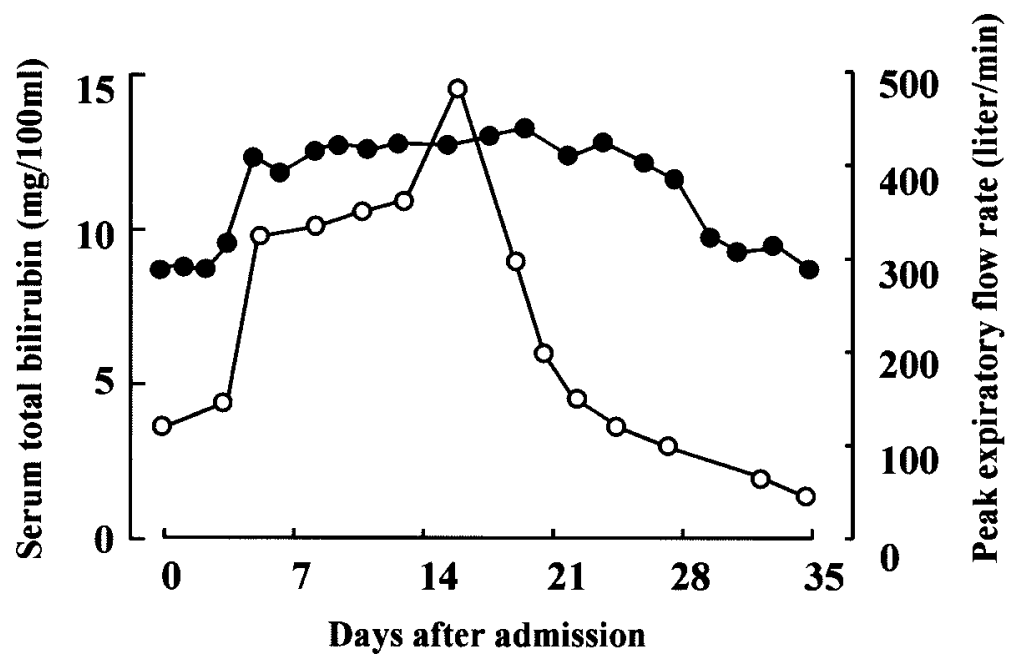

Fig. 1. Time course of serum total bilirubin and morning peak expiratory flow rate after admission. The morning peak expiratory flow rates (closed circles) were significantly improved compared with those at baseline condition in consistent with an elevation of serum bilirubin levels (open circles). 
ever, 4 weeks after admission, when the serum level of bilirubin decreased below $4 \mathrm{mg} / 100 \mathrm{ml}$, his asthma symptoms recurred and he had to resume anti-asthma medication to control his asthma symptoms. Finally, 5 weeks after admission, he recovered completely and was discharged without any complications.

\section{DISCUSSION}

The present case appears to be the first report describing a case of complete remission of difficult-to-control asthma during jaundice. The precise mechanism for this effect is unclear, but one possible mechanism is through hyperbilirubinemia and its antioxidant activity. Stocker et al. (1987) noted that bilirubin possesses strong antioxidant potential against peroxyl radicals and it is proposed that bile pigments function as natural antioxidants (Baranamo et al. 2002). In the present case, the asthma symptoms were relieved and an exhaled $\mathrm{CO}$ concentration, which is known as a marker for oxidative stress, was decreased to a normal range in association with an elevation of serum conjugated bilirubin. No other precipitating factors for asthma were identified during the observation period. Thus, the symptom-free interval during jaundice might be possibly explained by an antioxidant effect of bilirubin. The beneficial effect of bilirubin on asthma might be achieved at a concentration higher than $4 \mathrm{mg} / 100 \mathrm{ml}$, which is comparable to the effective concentration reported in experimental research (Stocker et al. 1987; Wang et al. 2002). Likewise, oxidative stress plays a critical role in the development of vascular disease. Several epidemiological studies have found that bilirubin levels are inversely associated with coronary artery disease and mortality from myocardial infarction. Gilbert's Syndrome is a genetic disorder of bilirubin conjugation leading to a mild unconjugated hyperbilirubinemia (Djousse et al. 2001). The incidence of ischemic heart disease in middle-aged individuals with Gilbert's Syndrome is reduced $>5$-fold compar- ed with the general population (Vitek et al. 2002). In the general population, high plasma bilirubin levels correlate with a reduced risk of coronary heart disease (Schwertner et al. 1994; Hopkins et al. 1996). Premature babies treated with supplemental oxygen suffer retinopathy of prematurity because of increased oxidative stress. In these patients, a higher serum bilirubin level is associated with diminished incidence of retinal damage (Heyman et al. 1989). A 10-year retrospective study of the Belgian population found serum bilirubin levels inversely related to cancer mortality (Temme et al. 2001).

We previously reported that bilirubin attenuated the disease progression in bleomycininduced pulmonary fibrosis in rats (Wang et al. 2002) and in a patient with exacerbations of idiopathic pulmonary fibrosis (Ohrui et al. 2001). Toward and Broadley (2002) reported that ozone caused an early-phase bronchoconstriction followed by a late-phase bronchoconstriction and increased respiratory rate. Furthermore, an increase in mucosal mast cells and increased histamine in guinea-pig airways has been reported immediately after ozone exposure (Murlas and Roum 1985). Bilirubin might give protection against oxidant-induced airway constriction through its anti-oxidant effect.

In the present case, the limitation of the interpretation of the effect of hyperbilirubinemia on the clinical course of asthma should be discussed. First, there is no information on the likely effects of hepatitis infection on the metabolism of all of the controller drugs, except theophylline. Although serum theophylline concentrations were not affected by $\mathrm{HB}$ virus infection, it is likely that hepatic metabolism of these drugs was considerably reduced during infection, and thus there would have been considerable accumulation of these drugs. This mechanism may well have played a role in the dramatic improvement. Second, there is no information about the induction or suppression of relevant cytokines, which could have been 
measured in serum specimens; such information would add considerably to mechanistic information. Finally, we did not evaluate serum levels of stress endocrines such as cortisol or epinephrine, which might affect the clinical course of asthma in this patient.

\section{Acknowledgments}

We thank Mr. Grant Crittenden for the English correction.

\section{References}

Baranamo, D.E., Rao, M., Ferris, C.D. \& Snyder, S.H. (2002) Bilirubin reductase: A major physiologic cytoprotectant. Proc. Natl. Acad. Sci. USA, 99, 16093-16098.

Dauletbaev, N., Rickmann, J., Viel, K., Buhl, R., Wagner, T.O. \& Bargon, J. (2001) Glutathione in induced sputum of healthy individuals and patients with asthma. Thorax, 56, 13-18.

Djousse, L., Levy, D., Cupples, L.A., Evans, J.C., D'Agostino, R.B. \& Ellison, R.C. (2001) Total serum bilirubin and risk of cardiovascular disease in the Framingham offspring study. Am. J. Cardiol., 87, 1196-1200.

Heyman, E., Ohlsson, A. \& Girschek, P. (1989) Retinopathy of prematurity and bilirubin. $N$. Engl. J. Med., 320, 256.

Hopkins, P.N., Wu, L.L., Hunt, S.C., James, B.C., Vincent, G.M. \& Williams, R.R. (1996) Higher plasma homocysteine and increased susceptibility to adverse effects of low folate in early familial coronary artery disease. Arterioscler. Thromb. Vasc. Biol., 16, 250-255.

Horvath, I., Donnelly, L.E., Kiss, A., Paredi, P., Kharitonov, S.A. \& Barnes, P.J. (1998) Raised levels of exhaled carbon monoxide are associated with an increased expression of heme oxygenase- 1 in airway macrophages in asthma: a new marker of oxidative stress. Thorax, 53, 668-672.

Kelly, F.J., Mudway, I., Blomberg, A., Frew, A. \& Sandstrom, T. (1999) Altered lung antioxidant status in patients with mild asthma. Lancet, 354, 482-483.

Murlas, C.G. \& Roum, J.H. (1985) Sequence of pathologic changes in the airway mucosa of guinea pigs during ozone-induced bronchial hyperreactivity. Am. Rev. Respir. Dis., 131, $314-320$.

Nakasato, H., Ohrui, T., Sekizawa, K., Matsui, T., Yamaya, M., Tamura, G. \& Sasaki, H. (1999) Prevention of severe premenstrual asthma attacks by leukotriene receptor antagonist. J. Allergy Clin. Immunol., 104, 585-588.

Ohrui, T., Higuchi, M., Kanda, A., Matsui, T., Sato, E. \& Sasaki, H. (2001) A patient with exacerbation of idiopathic pulmonary fibrosis which was resolved probably due to the coexisting hyperbilirubinemia? Tohoku. J. Exp. Med., 193, 245-249.

Schwertner, H.A., Jackson, W.G. \& Tolan, G. (1994) Association of low serum concentration of bilirubin with increased risk of coronary artery disease. Clin. Chem., 40, 18-23.

Stocker, R., Yamamoto, Y., McDonagh, A.F., Glazer, A.N. \& Ames, B.N. (1987) Bilirubin is an antioxidant of possible physiological importance. Science, 235, 1043-1046.

Temme, E.H., Zhang, J., Schouten, E.G. \& Kesteloot, H. (2001) Serum bilirubin and 10-year mortality risk in a Belgian population. Cancer Causes Control, 12, 887-894.

Toward, T.J. \& Broadley, K.J. (2002) Airway function, oedema, cell infiltration and nitric oxide generation in conscious ozone-exposed guinea-pigs: effects of dexamethasone and rolipram. Br. J. Pharmacol., 136, 735-745.

Vitek, L., Jirsa, M., Brodanova, M., Kalab, M., Marecek, Z., Danzig, V., Novotny, L. \& Kotal, P. (2002) Gilbert syndrome and ischemic heart disease: a protective effect of elevated bilirubin levels. Atherosclerosis, 16, 449-456.

Wang, H.D., Yamaya, M., Okinaga, S., Jia, Y.X., Kamanaka, M., Takahashi, H., Guo, L.Y., Ohrui, T. \& Sasaki, H. (2002) Bilirubin ameliorates bleomycin-induced pulmonary fibrosis in rats. Am. J. Respir. Crit. Care Med., 165, $406-411$.

Yamaya, M. (2002) Pathogenesis and management of virus infection-induced exacerbation of senile bronchial asthma and chronic pulmonary emphysema. Tohoku. J. Exp. Med., 197, $67-80$. 